\title{
Millennial science student teachers' views on decolonisation and culturally responsive teaching
}

\section{Thelma de Jager}

Department of Educational Studies, Tshwane University of Technology, Pretoria, South Africa

dejagert@tut.ac.za

https://orcid.org/0000-0002-6962-7974

(Received: 28 January 2019; accepted: 4 July 2019)

\section{Abstract}

Globally, the striving for decolonised education and acknowledgement of a nation's values, skills, beliefs, and acquisition of knowledge is being debated. In science education, the integration of cultural values and beliefs into the science curriculum is often ignored, which contributes to students being unable to express their individual views during interactive class discussions. This study therefore aimed to engage millennial science student teachers $(n=120)$ at a South African university in an action research study to express their views on decolonisation and culturally responsive teaching. The responses were categorised according to the themes of the Hernandez, Morales, and Shroyer (2013) model, which includes content integration, facilitation of knowledge construction, prejudice reduction, social justice, and academic development. The findings indicated that a cross-cultural perspective should be used (with balance between Euro-American centric sciences and indigenous knowledge from diverse cultures), that students should be instructed in their mother tongue, and that content needs to be connected to familiar everyday life experiences. The findings further amplified the importance of technology-assisted methods, the application of various integrated learning methods in science education, and inclusion in science curricula of the science role models of various cultures.

Keywords: decolonisation, cultural, prejudice, technology, indigenous knowledge, values

\section{Introduction}

The past 500 years of European nationalism have colonised science information and controlled perceptions, images, concepts, and constructions of reality-contributing to globalisation (Ani, 1994). Globalisation, which impels a system where local values are not recognised and materialism and individualism are advantaged (Hapanyengwi-Chemhuru \& Makuvaza, 2017), has led to an increase in diverse cultural encounters and a need for scientific literacy for all (van Eijck \& Roth, 2011). Thus, for student-centred science education that is based on the development of skills needed for the scientific workforce, diverse cultural values and experiences and the acquisition of science content knowledge within the context of the industrial world need to be effectively integrated in science curricula 
(de Feiter \& Ncube, 1999). Moreover, Mpofu, Otulaja, and Mushayikwa (2014) emphasised the importance of cultural alignment of the science curriculum with local cultures that includes beliefs, values, behaviours, experiences, and other characteristics of diverse cultures in achieving effective teaching and learning. The connection of science to students' real-life experiences can be seen as a cultural border crossing (Aikenhead \& Jegede, 1999).

Dos Santos (2009) argued that science teaching should commence where teachers identify students' cultural needs, and familiarise themselves with the sociocultural contexts in which their students have grown up. This would enable teachers to integrate students' diverse cultural values, interests, beliefs, and social contexts in science content and to discuss the cultural aspects identified. Elaborating on this view, Hernandez, Morales, and Shroyer (2013) used the term, culturally responsive science education, which refers to students' cultural experiences and their values or interests, and attempts to accommodate diverse cultures in science education. However, in the South African context, as in many other countries, science curricula mostly embrace Western knowledge while cultural knowledge is excluded (le Grange, 2016). In addressing this concern, the aim is to decolonise curricula by integrating diverse cultural values, norms, everyday life experiences, and historical developments with content knowledge. Decolonisation involves the dismantling, unlearning, and deconstruction of the dehumanisation of colonial oppression (Hapanyengwi-Chemhuru \& Makuvaza, 2017).

Globally and in South Africa, the need for decolonisation of education is being debated. What should institutions teach? Is the content of science curricula relevant to the needs of science students? This debate was enforced in South Africa through collective political actions that demanded the decolonising of university curricula by including diverse cultures' needs, in-sourcing workers and, ultimately, free education (Naicker, 2016). Decolonisation of academic curricula has become one of the central features of the demands of students and academics, and was evident in the University of Cape Town's Rhodes Must Fall protest action. The purpose of this action was to implement African cultural content, languages, and methodologies of education and learning, and to integrate Western content whenever relevant to African experiences (Kros, 2015). But, on the other hand, Jansen (2017) argued that if essential and powerful knowledge is reduced to everyday experiences of students, we deprive them of the quality education that enables them to engage in the world of science.

Considering the various perspectives of scholars, and the uncertainty about how to integrate decolonisation in science curricula, motivated the author to investigate: "What are the views of millennial science student teachers (growing up in a technology orientated world) concerning decolonisation and culturally responsive learning in science education?"

\section{Background}

Paulo Freire's (1970) humanistic philosophy acknowledged human values, and regarded knowledge as the product of human practices that transform the world. However, for centuries colonialism and imperialism deprived non-Europeans, Africa, and other countries, of their humanity and the development of their full potential (Settles, 1996). Wright and 
Maton (2004) added that colonialism also contributed to cultural division, political subjugation, and the loss of important natural resources. This gave rise to the decolonisation movement against colonial rule during the 1950s. Decolonisation can be defined as the process where the history of diverse cultures is recognised, and political independence obtained. The principle of decolonised education is to include all by recognising humanity and diverse cultural backgrounds, and by developing the intellectual capacity of all. In addition, it strives for the independence of a nation's values, skills, beliefs, and acquisition of knowledge. Despite the struggle for decolonisation in education since the end of the apartheid system, content knowledge and epistemologies at most South African institutions have not showed significant changes (Mungwini, 2017). Curriculum content still reflects Eurocentric and Western dominance, and privileges the cultures of minority groups (Heleta, 2016). The indigenous knowledge (IK) and cultural values of poor communities are seldom considered when teaching curricula (Mbembe, 2016).

Two decades ago, Aikenhead and Jegede (1999) maintained there was a need to review the pedagogy and development of culturally sensitive science curricula in supporting students to understand abstract concepts. Aikenhead (2008) agreed that the development of technology and Euro-American centric science have contributed to the development of science curricula and pedagogy that do not always consider diverse cultural norms, values, and ideologies. In addition, Gray (2014) argued that various integrated teaching and learning methods should be used to accommodate students' diverse cultural values (interests) and experiences when learning new science concepts.

After the dismantling of the apartheid education system, a period of rapid transformation and democratisation followed. Changes in science curricula were explicitly formulated to ensure access to education for previously disadvantaged students and to accommodate diverse cultures. The National Curriculum Statement for Science was constructed, based on Bloom's (1990) behavioural objectives (mental, cognitive, and science processes) and Piaget's theories (reasoning patterns; Anderson, Reder, \& Simon, 1996). This was followed by Curriculum 2005 (which partially included outcomes-based principles; Chisholm, 2003), the Revised National Curricula Statements, and the Curricula Assessment and Policy Statements (Department of Basic Education, 2012). The revision of policies aimed to teach relevant content knowledge from students' own cultural environment and equip them with skills to engage in dialogue with various sociocultural views. Dialogue in education is a human requirement to free oppressed people (Freire, 1970). During dialogue, teachers and students should be free to express their different views, values, norms, and cultural beliefs without forcing these on one another.

However, teaching and communication in English as a second language significantly influences science discourse (Pieretti \& Roseberry-McKibbin, 2016). Language is a vital component of culture, and contributes to effective science education. Akindele (2014) pointed out that in the Nigerian context, students and teachers use English and mother tongue to clarify difficult concepts with one another. In South Africa, the majority of students are not taught in their mother tongue, which contributes to students' difficulties in understanding 
abstract concepts or applying such concepts in real-life situations (Ferreira 2011). OwenSmith (2010) elaborated, stating that most parents still fear their children will not be able to participate in global economic growth if they are not instructed in English. This contributes to the persistence of the language learning barrier. Aikenhead (2008) asserted that science is best instructed when it is accessible and sensitive to diverse cultures. Carter and Dediwalage (2010) concurred, adding that a cross-cultural perspective should be used with a balance between Euro-American centric sciences and IK from diverse cultures. This implies that science teachers should select various integrated learning methods (Gray, 2014), and choose understandable socio-scientific issues derived from diverse values (Sadler, 2011) that could engage students in cultural discussions that contribute to the learning and understanding of scientific concepts (Lee, Yen, \& Aikenhead, 2012). Therefore, the pluralisation of knowledge is needed, based on an inter-cultural approach where all knowledge forms are included in the instruction of curricula content.

In South Africa and Zimbabwe, IK has been integrated in science classes through discussion of topics such as HIV/AIDS for gaining perceptions of the nature of science (Mpofu et al., 2014). This strategy is applied to address problems experienced locally and globally. Student teachers in Botswana are generally not willing to engage in discussions that are not within their life experience (Koosimile \& Suping, 2011). The integration of IK (science through art, ceremony and ritual) into Western science (use of instruments, standardised techniques, and research) can be related to culturally responsive teaching. Le Grange (2014) listed a few examples: South African San (Bushmen) traced the tracks of animals, and a tracker system was scientifically developed from their knowledge; aspirin was discovered through IK; Western modern science and Peruvian IK contributed to the creation of an aeroplane. In integrating IK in the curricula, it is essential that science teachers be familiar with the diverse sociocultural backgrounds of students in their classes because students' backgrounds differ and could affect their interactive engagement in class discussions (Suriel \& Atwater, 2012). IK and Western science should be integrated in a curriculum where culturally responsive science teachers are knowledgeable of diverse cultures and learning experiences in their classrooms.

\section{Theoretical foundation of culturally responsive science teaching}

The term culturally responsive science teaching can be associated with terms such as:

- culturally sensitive science, which recognises cultural similarities and differences that could affect students' learning, behaviour, and values (Aikenhead \& Jegede, 1999)

- culturally responsive pedagogy, which includes all students in equal education where the cultures of students are central for effective thinking, learning, and communication (Parsons, Foster, Gomillion, \& Smith Simpson, 2008)

- cross-cultural teaching, where the different cultures are compared and acknowledged by the dominant culture (Aikenhead, 2008). 
Considering the different terms used for diverse learning experiences, the term culturally responsive teaching, based on the model of Hernandez et al. (2013), was used as a foundation for this study. The model was compiled from a wide range of synthesised literature reviews and piloted among student teachers to investigate whether culturally responsive teaching is successfully applied in practice. It includes the following categorised themes:

- Content integration: include content from diverse cultures.

- Facilitation of knowledge construction: relate and construct new knowledge based on prior knowledge, and assist students in developing critical and independent thinking skills.

- Prejudice reduction: recognise the influence of contextual factors on learning and create a positive learning environment free of prejudice.

- Social justice: acknowledge diverse cultures, values, and norms in classrooms and adapt to changes.

- Academic development: create learning opportunities in the classroom that support all students' needs (Hernandez et al., 2013).

The relevance of the culturally responsive teaching model can be linked to the South African curricula, which aim to achieve academic success by effectively instructing school science cognisant of diverse cultural knowledge and values, free of prejudice. It is a pedagogy model that provides equitable access to education for students from all cultures and cultural orientations in all facets of learning.

\section{Methodology}

The study comprised an action-research investigation of South African science student teachers' perspectives on decolonisation and culturally responsive learning. Participants (lectured by the researcher) in this study were 120 first-year science student teachers at a university in South Africa, from diverse cultures and socio-contextual backgrounds. The ages of the participants ranged between 17 and 24 years of age with two participants above the age bracket.

\section{Data collection}

The data was collected using an action research approach. According to Zuber-Skerritt (2005), action research is participatory and collaborative, and typically arises from the clarification of concerns shared by the group. The aim of this action research was to exchange ideas and formulate conclusions on how diverse cultural needs could be integrated in science education. The research proceeded through six stages, as illustrated in Figure 1. 


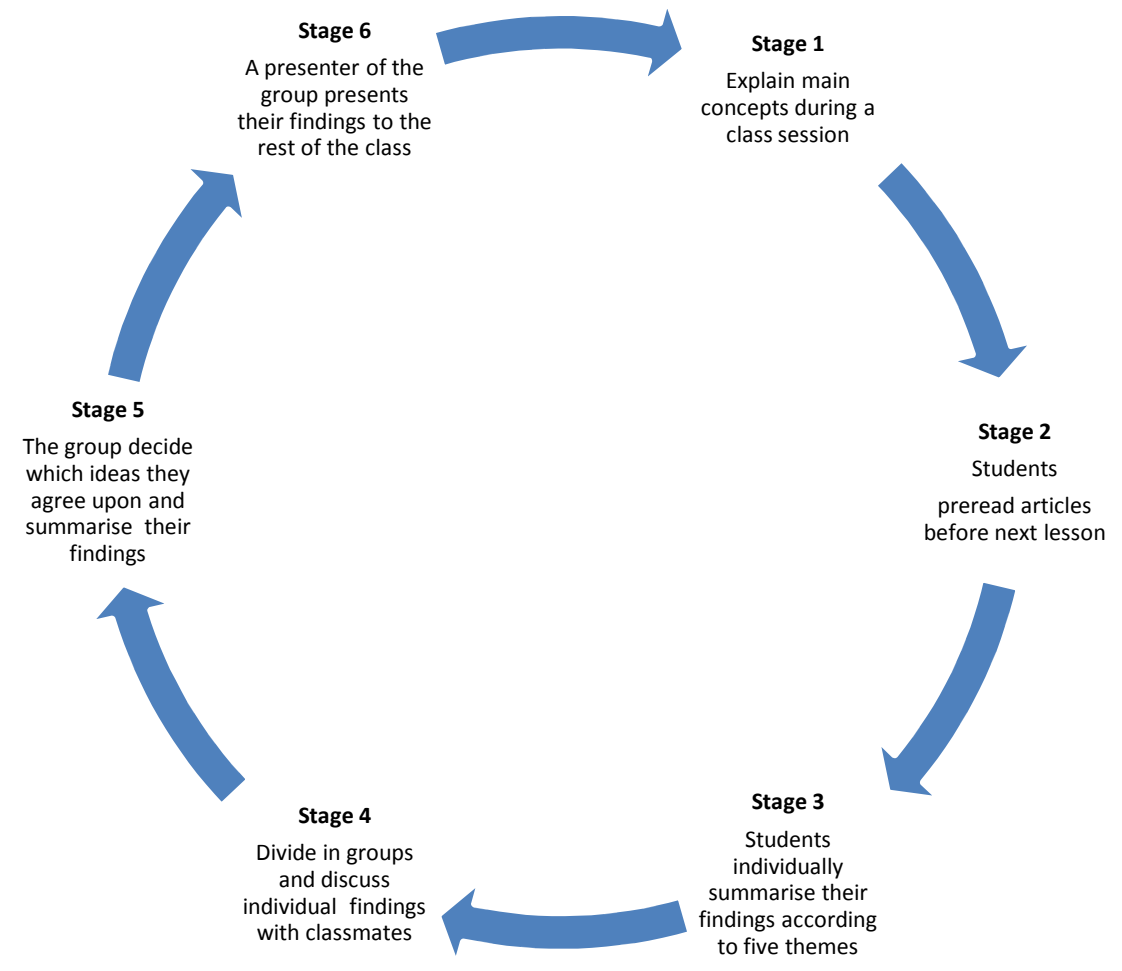

Figure 1: The action research cycle

In the first stage, the concepts, decolonisation and culturally responsive teaching, were discussed during a class session of the researcher, using the model of Hernandez et al. (2013), which consists of five thematic categories: content integration, facilitation of knowledge construction, prejudice reduction, social justice, and academic development. Unclear concepts were clarified by the researcher. In the second stage, participants were provided with recommended articles to preread, and requested to use their own resources (additional articles, interviews with family members or academics) in conducting individual research on decolonisation and culturally responsive teaching. During the third stage, students had to construct and summarise their own views on what they had read, observed, or heard during their interviews, being mindful of the five themes of the Hernandez et. al (2013) model. In the fourth stage, students were grouped into 12 groups of 10 students, and assigned to discuss their individual findings within their groups. During Stage 5, the group collaboratively decided on their views concerning decolonisation and how cultural information could effectively be integrated in science education. In the last stage, a selected speaker from each group was given 10 minutes to present a summary of their group's findings. During the class discussions, the researcher observed, tape-recorded the presentations of all groups, and transcribed responses in themes related to the culturally responsive teaching model of Hernandez et al. (2013). Some groups repeated similar views during their presentations. To avoid duplication, views were recorded verbatim once.

In assuring that data was valid, unbiased, and reliable, diverse views were assessed according to the observed genuineness and honesty of students' perceptions. During the data analysis process, the researcher substantiated validity by detecting whether the data accurately represented the posed questions, and by examining contradictory responses. This was done to 
prevent bias and altered interpretations by the researcher. Furthermore, after analysing data, the findings were posted on the students' online blackboard for them to re-analyse data interpretations. The feedback of participants was important for the researcher in detecting possible false and misinterpreted data.

\section{Presentation and analysis of data}

\section{Responses to Question One: "What is your view on decolonisation?"}

Most of the groups $(n=9)$ indicated that they needed cultural values, norms, and their cultural experiences to be included in the science curricula and integrated with Western science. Three groups were totally against the idea, stating that they wished to be part of technology development and globalised content. None explicitly indicated that they supported the idea of a decolonised science curriculum where no Western knowledge or technology was included. Responses indicated that decolonisation of content would enable African learners to understand who they are, where they come from and currently are:

Learners should firstly be taught science content related to their own backgrounds and cultures and once they know their own cultural history, they can be exposed to European and Western science content knowledge.

There are good practices, content, and African cultural traditions that support the upbringing of the young ones, which is important to include in the current science teaching practices.

It is imperative to relate content to each learner as a unique individual who grew up with their own life experiences as this is needed as a foundation for further learning. However, the science content instructed in the classroom must also be integrated with the application of the latest and best technology skills so that learners can stay abreast with international development.

Starting to learn new concepts from your community could improve learning as learners are already familiar with their own learning environment where they grew up.

Decolonisation is needed where science learners are taught values, norms, and morals and traditions of their own cultures and the environment they live in. The reason being that they could develop a sense of responsibility in making critical decisions that affect their lives and that of the future generations.

No, it is a horrific idea. Globally, communities are revolving and changing according to new technology and newly discovered content, and we as students will fall behind in developing new skills and science knowledge. 
Responses to Question Two: "How can culturally responsive teaching be enhanced in the teaching and learning of science?"

Perspectives of participants in response to this question related mostly to the five principles of the Hernandez et al. (2013) culturally responsive model. The reason could be that the lecturer had discussed culturally responsive teaching during the first stage of the action research, referring to the principles of that model, which may have guided responses. In addition, during the second stage, students had to preread several articles (prescribed and not prescribed) related to culturally responsive teaching. The model was probably discussed in more than one of these articles. Therefore, the principles of the model (content integration, facilitation of knowledge construction, prejudice reduction, social justice, and academic development) were used to categorise the views of participants below.

\section{Content integration}

In all groups, it was mentioned that they needed familiar concepts and traditional experiences they had previously learned in their communities to help them understand abstract concepts. Thus, most participants indicated that the integration of cultural knowledge in the science curriculum was a requirement for effective teaching:

Learners feel comfortable to engage in group discussions when they discuss familiar concepts but draw back once they are confronted to discuss unfamiliar culturally related concepts.

Once they have learned basic skills from their own community, learners will be able acquire content knowledge from other countries.

Integrate cultural knowledge into the existing curriculum. For example, dung and water can be mixed to pave in front of houses rather than bricks. In the past, our grandparents used to add water or any vegetables to food to remove excess salt. In chemistry, we learn about various types of separation. For instance, if you poured too much salt in the meat you can heat the meat up until the water evaporate in the pot then you take the meat out of the pot and the salt will remain in the pot.

Existing content should be integrated into the traditional experiences of learners on how to sustain their environment.

Learners should engage more in collaborative group discussions where they can share their beliefs and cultural traditions with other cultures.

\section{Facilitation of knowledge construction}

Most groups $(n=10)$ indicated that learners should be instructed by connecting new content to what they know, and with everyday life experiences. Three groups also stated that they needed more technology-assisted methods to facilitate science education effectively: 
It is important to commence your learning with what you know best and then gradually learn about the rest of the world.

Science content instructed in class should be assisted with technology methods, and teachers need to receive regular training on the latest available online science programmes.

Teach learners from the known (community, values, skills, habits, etc.) to the unknown. Learners will be able to identify the gaps in content knowledge and construct content knowledge that will best suit their community.

Use relevant topics in science education to assist learners in developing the skills to work collaboratively in solving problems and participate in the economic and technology development.

Content should be related to learners' everyday experiences, such as AIDS, tuberculosis, malaria, and cultural medications that are developed to treat these illnesses.

\section{Prejudice reduction}

Of all the themes, prejudice reduction seemed central in many of the discussions, and a variety of concerns and needs were raised by all groups. The groups emphasised that teachers needed to acknowledge the values and norms of diverse cultures, and the injustices of the past, in their classes. They felt that teachers should teach students to respect one another for who they are and use more examples of role models of various cultures who have contributed to science in the curriculum:

Knowing different cultures and the backgrounds of learners could contribute to effective support for learning barriers.

Learners should not only know other cultures but also their own culture. Growing up in a minority dominated society causes many learners to forget their own heritage and culture.

Opportunities should be created where learners are allowed to construct content knowledge in investigating scientific phenomenon in the community in which they grew up. Learners should be encouraged to question and listen to the cultural stories told by their family members.

Teach learners that although we don't all look or act in the same way, we are still all alike and live according to specific values in life.

Teachers' teaching approaches should accommodate the diverse cultures in the classroom. 
Teach all learners to respect all cultures and the people that they will interact with once they leave school.

Decolonisation and acknowledgement of diverse cultural values will assist learners to gain confidence and respect for who they are.

Teachers should acknowledge discriminations and injustices of the past during instruction but teach for the present and for the future as learning content cannot be static.

Moral values, norms, and traditions of the society should be taught and included in class discussions.

Teachers need professional training in how to address diverse cultural groups in their classes.

Include examples of multicultural role models' contributions to science content to illustrate that all ethnicities contribute positively to education.

\section{Social justice}

Similar responses were presented by most groups, indicating that participants were in agreement concerning their views on social justice. It was stated that:

Learners should be allowed to speak in their mother tongue and discuss concepts with their peers in a language that is familiar to them ( $n=4$ groups).

Diverse cultures based on differences in values and beliefs should not be judged by the teachers or learners. Learners should be allowed to share their experiences, fearless, at home with the rest of the class and allow others to view their cultural traditions and practices ( $n=7$ groups).

Teachers should come from different cultures and backgrounds, have enough experience in integrating multicultural features into science instruction, and be a role model by emphasising changes within a democratic society that respects human rights ( $n=6$ groups).

\section{Academic development}

Most presenters indicated that textbooks should illustrate more examples of diverse cultures and a variety of science teaching methods should be employed. Specific reference was made of enquiry methods into the historical past, which are considered essential for learning more about role models from own cultures who had contributed to science content. Student teachers expressed the opinion that academic performance could improve if teachers considered the following aspects: 
Learners who learn what is well known to them grasp content easier and without learning challenges.

The classroom environment should display images, traditions, and word charts in different languages of different cultures relating to the science curriculum.

The pictures against the walls should not only resemble minority groups, this can help learners to relax and learn at their best.

Textbooks that we learn from should include more examples with images and content that reflects different cultures that learners can identify and connect their current knowledge with what they have to learn in class.

Teachers need to use a variety of teaching methods, which includes enquiring methods of the historical past.

Learners attending schools where their own culture is the minority group could feel they need to set aside their own traditions and norms to be accepted by their peers. This can cause learners to feel left out, and affect their academic performance as they don't or cannot engage in class discussions, do not develop socially and emotionally.

Academic performance can be enhanced in using culture-specific related science content and including examples of diverse cultural contributions to science.

Acknowledging the contribution of diverse cultural content to science education could develop learners' self-esteem and their academic learning as they do not fear to voice their opinions and are more relaxed in classes when learning.

\section{Discussion and recommendations}

The views of these millennials growing up with technology were not surprising; none wanted to be excluded from opportunities to develop technological skills and Western scientific knowledge. Most participants commented that they needed a science curriculum in which their cultural values, norms, and history were integrated with global knowledge and skills. They indicated that science education should recognise each person's individuality, allow them to grow up according to African traditions, learn from their cultural life experiences, stay familiar with the historical development of their own culture, teach them the values, norms, morals, and traditions of their own cultures and the environment they live in, and assist them to develop a sense of responsibility for what is expected of them as accountable citizens. These responses coincide with those of le Grange (2016), Mpofu et al. (2014), and Dos Santos (2009) who stated that teachers need to identify students' cultural needs, beliefs, values, norms, and traditions, and include these in curricula content to achieve effective teaching and learning. On the other hand, some presenters indicated that learners also needed exposure to European and Western science content knowledge and technology skills in order to stay abreast with global development. Although globalisation centres on individualism and 
materialism (Hapanyengwi-Chemhuru \& Makuvaza, 2017), students wish to develop scientific literacy and be able to participate in global issues (van Eijck \& Roth, 2011). Three groups unambiguously despised the idea of decolonisation, indicating that while globally all communities are evolving and changing, decolonisation would cause them to stay behind in the development of new science content and technology skills. In conclusion, it can be said that participants wanted to remain familiar with their cultural norms, values, and traditions but they also wanted to be part of the other millennials growing up with technology and newly discovered scientific phenomena.

Responses related to culturally responsive teaching were grouped according to the principles of the model proposed by Hernandez et al. (2013). Views according to the first principle, content integration, indicated that learners need to acquire basic skills from their own culture before they are able to acquire new colonial content knowledge, and that they prefer to engage in collaborative group discussions where they can share familiar life experiences with other cultures rather than to engage in unfamiliar culture-based discussions. This is important in view of le Grange's (2014) observation that cultural values and IK of poverty-stricken communities are not always included in curricula. The student teachers' responses accord with those of Sadler (2011) and Lee et al. (2012), who stated that interesting topics deriving from students' experiences should be included in curricula in order to encourage active learner engagement in discussions. In addition, participants pointed out that teachers should integrate cultural knowledge and everyday real-life experiences into the science curriculum, for example, dung and water for paving, and food cooking to teach the concept of separation in chemistry. Furthermore, Gray (2014) and Carter and Dediwalage (2010) proposed that various integrated learning methods should be employed, where IK and Euro-American centric sciences are integrated in the curriculum using a cross-curricular perspective. This is in accordance with the overwhelming response of participants that teachers need to facilitate learning by connecting students' cultural experiences with science content in their curricula.

The comments associated with the facilitation of science knowledge construction reveal that the teacher needs to commence teaching with what science learners know (community, values, skills, habits, etc.) and gradually continue onto unknown content, and relate to interesting everyday life experiences of learners in clarifying abstract concepts. For example, how medication traditionally developed in their cultures to treat or prevent sicknesses such as flu, AIDS/HIV, tuberculosis, malaria, and others. A plausible reason why most participants requested concepts derived from their cultures could be that curriculum content still privileges minority groups and is dominated by Eurocentric and Western groups' cultural beliefs and values (Heleta, 2016). Although tradition, values, and norms are significant in learning science content, it was also suggested that relevant topics be included in the science curriculum to enable learners to discuss and work collaboratively in solving problems in order to participate in economic and technology growth. This can be aligned with Suriel and Atwater (2012), who expressed the opinion that diverse backgrounds of students affect interactive class discussions, and could inhibit students from working collaboratively when learning. It is significant that three groups demanded the facilitation of science teaching by using technology-assisted methods. In summarising the responses, the conclusion can be 
drawn that an inter-cultural approach of IK and modern science could facilitate science knowledge construction.

Comments related to prejudice reduction suggested that committed science teachers should be able to acknowledge discrimination and injustices of the past, but would teach for the present and for the future. Moreover, they should be able to acknowledge diverse cultural values and promote decolonisation by helping learners gain self-confidence for who they are, apply teaching approaches that accommodate the diverse cultures in class, and teach all learners to respect all cultures. These views can be related to culturally sensitive science, where teachers recognise differences and similarities in diverse cultures that could impact on students' behaviour, values, and effective learning (Aikenhead \& Jegede, 1999). Students wished to be taught about their own heritage and culture by investigating scientific phenomena within the social contexts in which they grew up. Additionally, it was suggested that they could conduct interviews with older people or family members to tell them more about their own history and cultural traditions. It is noteworthy that one of the groups commented on extra support for learners encountering learning barriers, especially the second language barrier. Pieretti and Roseberry-McKibbin (2016) propounded that English as a second language could influence science discussions of students significantly. Lastly, it was noted that student teachers do not receive sufficient professional training in how to instruct diverse cultures in their classes.

Views of participants also indicated that there is a need for social justice in classrooms. Issues that were raised included: learners be allowed to communicate and engage in discussions using their mother tongue and not a second language; learners should not fear to be judged on their diverse beliefs, values, and backgrounds but should be allowed to share their cultural traditions and life experiences with their classmates; learners should be taught by teachers from diverse cultures who acknowledge and exemplify a democratic society and respect human rights. Most of these perspectives can be connected to a culturally responsive pedagogy that includes equal education for all and the centralising of students' diverse cultures to enable them to engage in effective learning, thinking, and communication (Parsons et al., 2008).

Various effects of culture-responsive teaching on learners' academic development were raised. It was felt that learners would experience fewer learning challenges when they learnt content that was familiar to them. This is in agreement with Sadler (2011), who pointed out that teachers should select understandable socio-scientific topics derived from diverse values. Some of the presenters of the groups mentioned that a facilitative classroom environment is important, with word charts written in diverse languages and images illustrating various cultures and not only one culture to ensure learners are at ease when learning. Science textbooks should also illustrate images and content of diverse cultures. Moreover, in alignment with Gray (2014), teachers should employ a variety of teaching methods that include inquiry methods learners can use to learn from their historical past and to develop the self-esteem necessary to engage in class discussions and express their own cultural views. In recognising the contributions of diverse cultures to science education (Lee et al., 2012), 
teachers could limit learners' fear of voicing their opinions in class discussions and help them to develop a positive self-esteem that results in successful academic performance. Most presenters said they had not acquired academic success because of unfamiliar content taught in a second language. More than half of the participants pointed out that they wanted teachers to use a variety of teaching approaches, textbooks, and wall charts that illustrated images of various cultures' role models. One group stated that cultural content should be included in the science curriculum for enhancing learners' self-esteem and academic development.

This study shows that valuing students' cultural capital (the sociocultural context in which they grew up) is important for effectively engaging students in science education.

\section{Conclusion}

The decolonisation movement in which political independence is obtained, and in which diverse cultures, norms, and values are included in science education, was supported by the majority of student-teacher participants in this study. It can be concluded that university teachers need to review their practices to address the needs of students. Social justice has to be addressed so that students commence their learning with what is familiar to them, and communicate in their mother tongue to achieve academic success. Respondents agreed that prejudice against cultures needs to change so that different cultures respect one another and recognise diverse cultural values, beliefs, and norms. This would contribute to students feeling respected and not judged because of their background when engaging in interactive class discussions. Cultural respect can further be enhanced if teachers act as role models of a democratic society and create learning opportunities where students can share their cultural traditions and life experiences with classmates.

Various approaches could be used by teachers to allow all students to function productively and sensitively when learning in an intercultural environment. For example, discuss and refer to the contributions to science content knowledge of role models from diverse cultures, and use science textbooks that illustrate and recognise diverse cultural norms and values. In addition, as millennials growing up with technology, students also articulated the importance of the integration of technology-assisted methods in science teaching and learning. It follows that a combination of cultural and Western orientated learning (inter-cultural approaches) could facilitate science knowledge construction.

In conclusion, student teachers indicated that while they wanted to stay familiar with their own cultural norms, values, and traditions, they also wanted to be part of the other millennials who grew up with technology and newly discovered scientific phenomena. They did not want to be left behind, and wished to be significantly exposed by means of inquiring approaches to discover and learn about scientific concepts and to develop the latest technological skills. Therefore, diverse technology-assisted teaching approaches that enable students to stay abreast of global technology development should be integrated in culturally responsive science teaching and learning. 


\section{References}

Aikenhead, G. A. (2008, February). Importation of science programs from Euro-American countries into Asian countries and regions: A recipe for colonization? Keynote paper presented to the Conference of Asian Science Education, Kao-hsiung, Taiwan.

Aikenhead, G. S., \& Jegede, O. J. (1999). Cross-cultural science education: A cognitive explanation of a cultural phenomenon. Journal of Research in Science Teaching, $36(3), 1-20$.

Akindele, M. I. (2014). Poverty of primary education in Nigeria: The way forward. Education 3-13, 42(6), 637-647.

Anderson, J. R., Reder, L. M., \& Simon, A. (1996). Situative versus cognitive perspectives: Form versus substance. Educational Researcher, 26(1), 18-21.

Ani, M. (1994). Yuruga: An African-centered critique of European thought and behavior. Trenton, NJ: African World Press.

Carter, L., \& Dediwalage, R. (2010). Globalization and science education: The case of sustainability by the Bay. Cultural Studies of Science Education, 5(2), 275-291.

Chisholm, L. (2003). The state of curriculum reform in South Africa: The issue of Curriculum C2005. In R. Southall, A. Habib, \& J. Daniel (Eds.), State of the nation: South Africa 2003-2004. Pretoria, RSA: HSRC.

de Feiter, L. P., \& Ncube, K. (1999). Toward a comprehensive strategy for science curriculum reform and teacher development in Southern Africa. In S. A. Ware (Ed.), Science and environment education: Views from developing countries (pp. 177-198). Washington, DC: World Bank. Retrieved from ttp://web.worldbank.org/archive/website00243B/WEB/PDF/WARE1999.PDF

Department of Basic Education. (2012). The curriculum and assessment policy statement (CAPS): Natural Science Grade Nine. Pretoria, RSA: Author.

Dos Santos, W. L. P. (2009). Scientific literacy: A Freirean perspective as a radical view of humanistic science education. Science Education, 93, 361-382.

Ferreira, J. G. (2011). Teaching life sciences to English second language learners: What do teachers do? South African Journal of Education, 31(1), 102-113.

Freire, P. (1970). Pedagogy of the oppressed. New York, NY: Herder \& Herder.

Gray, R. (2014). The distinction between experimental and historical sciences as a framework for improving classroom inquiry. Science Education, 98(2), 327-341. 
Hapanyengwi-Chemhuru, O., \& Makuvaza, N. (2017). Re-thinking education in postcolonial Africa. In E. Shizha, \& N. Makuvaza (Eds.), Re-thinking postcolonial education in Sub-Saharan Africa in the 21 st century. Rotterdam, Netherlands: Sense.

Heleta, S. (2016). Decolonisation of higher education: Dismantling epistemic violence and Eurocentrism in South Africa. Transformation in Higher Education, 1(1), 1-8.

Hernandez, C. M., Morales, A. R., \& Shroyer, M. G. (2013). The development of a model of culturally responsive science and mathematics teaching. Cultural Studies of Science Education, 8(4), 803-820.

Jansen, J. D. (2017). As by fire: The end of the South African university. Cape Town, RSA: Tafelberg.

Koosimile, A. T., \& Suping, S. M. (2011). Pre-service teachers' attempts at debating contemporary issues in science education: A case study from Botswana. International Journal of Educational Development, 31, 458-464.

Kros, C. (2015). Rhodes must fall: Archives and counter-archives, Critical Arts, 29(1), 150165.

Lee, H., Yen, C.-F., \& Aikenhead, G. S. (2012). Indigenous elementary students's science instruction in Taiwan: Indigenous knowledge and western science. Research in Science Education, 42(6), 1183-1199.

le Grange, L. (2014). Currere's active force and the Africanisation of the university curriculum. South African Journal of Higher Education, 28(4), 1284-1294.

le Grange, L. (2016). Decolonising the university curriculum. South African Journal of Higher Education, 30(2), 1-12.

Mbembe, A. J. (2016). Decolonizing the university: New directions. Arts \& Humanities in Higher Education, 15(1), 29-45.

Mpofu, V., Otulaja, F. S., \& Mushayiwa, E. (2014). Towards culturally relevant classroom science: A theoretical framework focusing on traditional plant healing. Cultural Studies of Science Education, 9(1) 221-242.

Mungwini, P. (2017). The question of epistemic justice: Polemics, contestations and dialogue (Inaugural lecture). Retrieved from University of South Africa website http://uir.unisa.ac.za/bitstream/handle/10500/23193/Inaugral\%20Lecture_mungwini_ August\%2024_2017\%201.pdf?sequence=1\&isAllowed=y

Naicker, C. (2016). From Marikana to \#feesmustfall: The praxis of popular politics in South Africa. Urbanisation, 1(1), 53-61. 
Owen-Smith, M. (2010). The language challenge in the classroom: A serious shift in thinking and action is needed. Retrieved from Helen Suzman Foundation website https://hsf.org.za/publications/focus/focus-56-february-2010-on-learning-andteaching/the-language-challenge-in-the-classroom-a-serious-shift-in-thinking-andaction-is-needed

Parsons, E. C., Foster, S., Gomillion, C. T., \& Smith Simpson, J. (2008). Diversity knowledge in science teacher education-translating concept to instruction: An example specific to African Americans. Journal of Science Teacher Education, 19(1), 69-83.

Pieretti, R. A., \& Roseberry-McKibbin, C. (2016). Assessment and intervention for English language learners with primary language impairment: Research-based best practices. Communication Disorders Quarterly, 37(2), 117-128.

Sadler, T. D. (2011). Situating socio-scientific issues in classrooms as a means of achieving goals of science education. In T. Sadler (Ed.), Socio-scientific issues in the classroom: Teaching, learning and research (pp. 1-9). Dordrecht, Netherlands: Springer.

Settles, J. D. (1996). The impact of colonialism on African economic development. University of Tennessee Honors Thesis Projects. Retrieved from https://trace.tennessee.edu/utk_chanhonoproj/182

Suriel, R. L., \& Atwater, M. M. (2012). From the contribution to the action approach: White teachers' experiences influencing the development of multicultural science curricula. Journal of Research in Science Teaching, 49(19), 1271-1295.

van Eijck, M. W., \& Roth, W.-M. (2011). Cultural diversity in science education through novelization: Against the epicization of science and cultural centralization. Journal of Research in Science Teaching, 48(7), 824-847.

Wright, H. K., \& Maton, K. (2004). Cultural studies and education: From Birmingham origin to glocal presence. Review of Education, Pedagogy, and Cultural Studies, 26(3), 7389.

Zuber-Skerritt, O. (2005). New directions in action research. Bristol, PA: Falmer Press. 